\title{
Intrauterine Capsule Dosage Form
}

National Cancer Institute

\section{Source}

National Cancer Institute. Intrauterine Capsule Dosage Form. NCI Thesaurus. Code C149613.

Solid single-dose preparation for veterinary use consisting of a soft capsule containing a liquid or semi-solid preparation intended for intrauterine use, including preparations releasing their contents over an extended period of time. 